\title{
The Effects of Regional Free Trade Agreements on Industrial Structure: An Extension of Krugman's Economic Geography Model (1991)
}

\author{
Jung Hur \\ National University of Singapore
}

\begin{abstract}
Extending Krugman's (1991) economic geography model, this paper examines the stability of an industrial structure resulting from the production shifting-in effect of the formation of regional trade agreements. This paper claims that nonhigher external trade costs against non-member countries may be needed in order to secure the divergence of industries into the area of a regional trade agreement.
\end{abstract}

- JEL Classifications: F12, F15

- Key words: Economic geography, Regional trade agreements

\section{Introduction}

Recently the question of how the formation of regional trade agreements (RTAs hereafter) affects the location of industry has been studied by a group of economic geography theorists including Baldwin and Venables (1995) and Puga and Venables (1997). They argued that when some countries form an RTA, production is expected to shift into the RTA. They called it the "production shifting-in effect" of the RTA.

One way to prove their findings is to investigate an increase in the inflows of foreign direct investments into the regional free trade areas from the rest of the world. For instance, see Figure 1 for the time series of FDI inflows of the original

*Corresponding address: Professor Jung Hur, Department of Economics, National University of Singapore, 10 Kent Ridge Crescent, Singapore, 117570. Tel: +65-6874-4873, Fax: +65-6775-2646, Email: ecshurj@nus.edu.sg

(C2003-Center for International Economics, Sejong Institution, All Rights Reserved. 
Figure 1. FDI Inflows of EC

FDI inflows in EC(original 15 members since 1958)

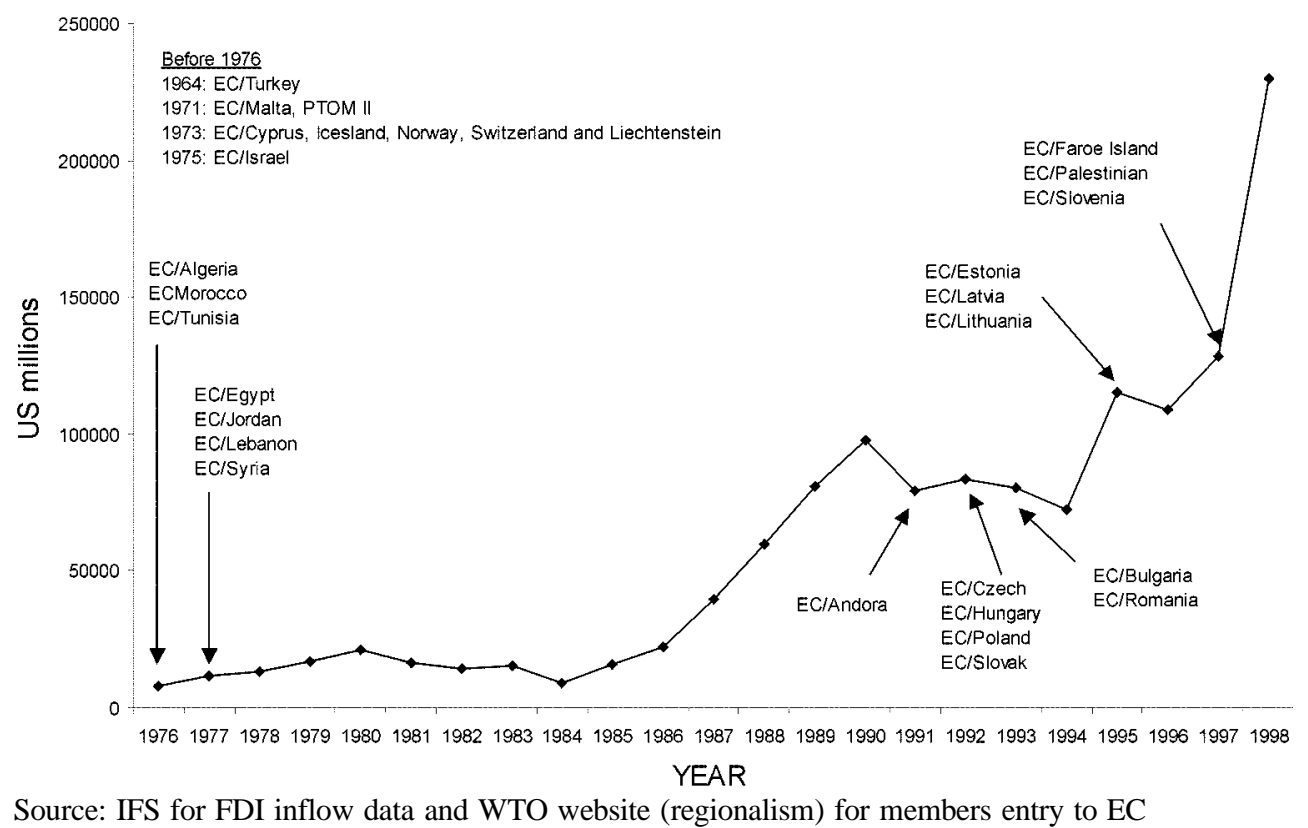

15 member countries (signed in as of 1958) in the EC from 1976 to 1998. It is clearly demonstrated that the EC has attracted a large amount of foreign direct investments. So, the data seem to support their theoretical finding. However, ironically, it is also true that there has been an increase in FDI outflows from the EC to the rest of the world for the same range of years (see Figure 2). So, the empirical evidence of the production shifting-in effect of the RTA seems ambiguous.

This paper tries to fill the gap between their theoretical findings and the data, by re-investigating the theories of economic geography and regional integration. In particular, this paper shows that the industrial structure resulting from the production shifting-in effect of an RTA, to be stable, may need non-higher external trade costs between the RTA and other non-RTA countries.

In order to explain the spatial differences of production structure in an economic geography model, it is essential to include elements such as the increasing returns to scale, positive trade costs and imperfect competition. Krugman (1991) and Krugman and Venables (1995) had such common features in their models and showed how they created core-periphery structures through externalities among economic agents. One of the main differences between the two papers is their assumption of factor mobility. In Krugman (1991), where workers are mobile, an 
Figure 2. FDI Outflows of EC

FDI outflow in EC(original 15 members since 1958)

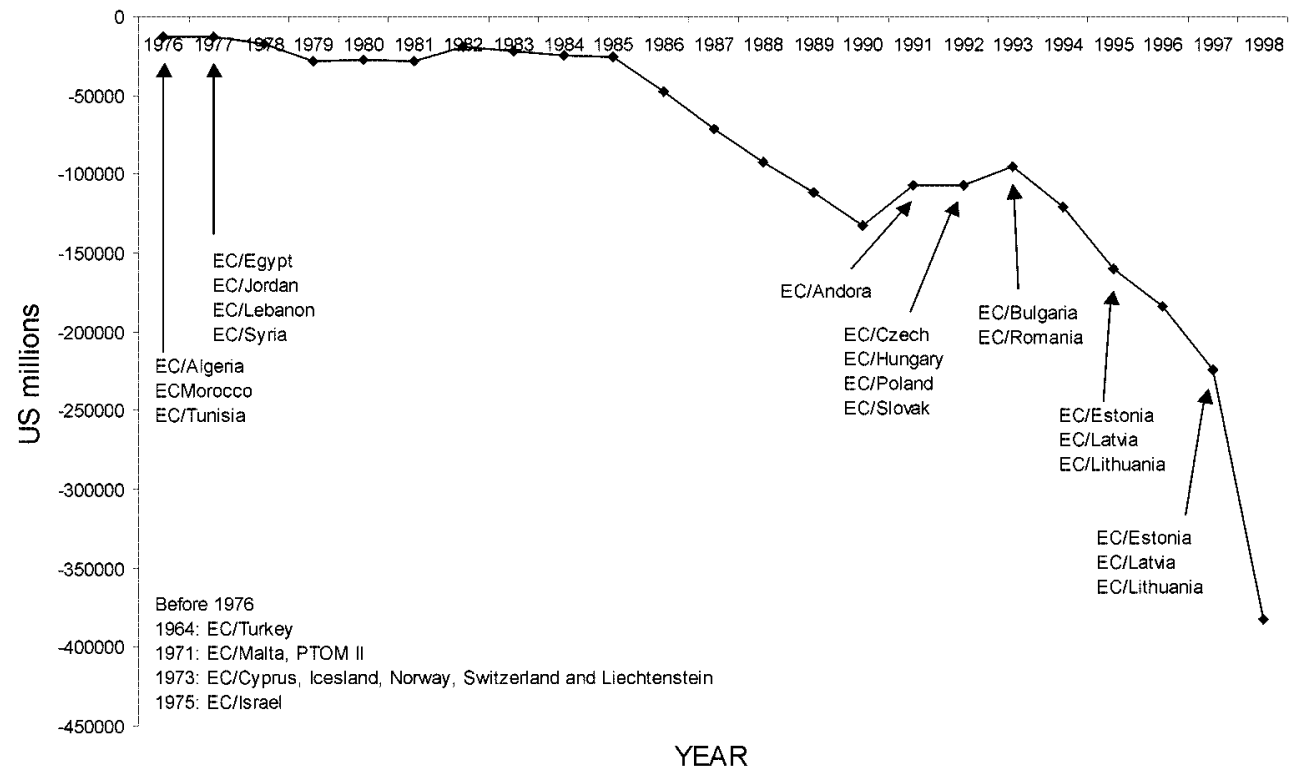

Source: IFS for FDI outflow data and WTO website (regionalism) for members entry to EC

industrial firm needs a unit of worker to produce an output, so when the firm moves to a place, it increases labor demand in that place, which increases the wage rate, and the higher wage in turn will attract workers to move to that place. However, in Krugman and Venables (1995), where workers are not mobile between countries, a firm is not only a final goods' supplier to consumers but also an intermediate goods' demander and supplier. When a firm moves to a place, it increases the intermediate goods' demand in that place, which increases its price. The higher price of the intermediate goods will attract another intermediate firm to move to that place.

Puga and Venables (1997) extended Krugman and Venables (1995) to a model of multiple nations. They made several comparative static analyses of exogenous trade barriers among countries and of their impact on firms' profitability. The two main results are as follows. First, in a symmetric case with positive trade costs, when the internal trade barriers begin to drop between two RTA countries, the firm outside the RTA starts to move inside because of the higher profits created by lower trade-cost advantages. They acknowledged a similar finding by Baldwin and Venables (1995). Second, what is novel in their paper is that, when the internal trade barriers continue to drop to zero, even within the regional integration, there 
occurs a local industrial concentration in one member of the RTA. Puga and Venables' results are insensitive to a later change in the level of external trade barriers. As a final producer, a firm inside an RTA would always have a cost advantage as long as the internal trade costs are smaller than the external trade costs as a result of the formation of a regional trade agreement. However, the present paper claims that such insensitivity may need to be recons-idered.

To demonstrate this, I extend Krugman's (1991) economic geography framework to incorporate multiple nations. Unlike the model developed by Krugman and Venables (1995), Krugmans' (1991) model assumes, first, that workers are mobile between countries and peasants are immobile, second, that both workers and peasants are all consumers in the economy, and third, that firms are the final goods' producers.

First, I replicate the "production shifting-in" effect of an RTA in the extension of Krugman's model. That is, given a positive and symmetric level of all trade costs among countries, the preferential removal of internal trade costs between RTA members causes a production shift into the RTA region. This result confirms the production shifting-in effect that has been argued for in the economic geography model.

Next, in order to check the stability of the industrial structure which results from the production shifting-in effect and which is subsequently influenced by an increase in the external trade costs, I consider initially a stable asymmetric equilibrium in which (1) all workers and manufacturing firms are concentrated in one of the RTA countries, (2) the exogenously given internal trade costs between the RTA countries are zero, and (3) the exogenously given external trade costs between the RTA and its non-RTA trading partners are positive. Note that this is very similar to the industrial structure resulting from the production shifting-in effect in Puga and Venables (1997). I show that, all other things being equal, this equilibrium becomes unstable if the exogenously given external trade costs become higher than the level in (3). The intuition for this result is as follows. In order to attract a worker to move to a non-RTA country, the defecting firm has to compensate the worker with a higher wage. The higher wage will increase the firm's profit-maximizing price in the non-RTA country. Then the firm's revenues will increase relatively more than the increases in its costs embodied in the higher wage, since not only the worker but also the peasants who are living in the country have to pay the higher price.

The rest of the paper proceeds as follows. In section 2, I will extend the simple 
model suggested by Krugman (1991) to include multiple nations, and characterize the short run and long run equilibrium. In section 3, I show the "production shifting-in effect" of the formation of an RTA in the economic geography model. In section 4, I show that the industrial structure resulting from the production shifting-in effect may become unstable if there is a later increase in the external trade costs. Section 5 presents the conclusion.

\section{The Model of Economic Geography with Multiple Countries}

\section{A. The Basic Model (an Extension of Krugman (1991))}

Consider a trading system with $M$ countries. In each country, there are two production sectors; a commodity sector and an industrial sector. The commodity sector is perfectly competitive. It produces products under constant returns to scale, using one unit of labor per unit of output. The goods are homogenous and costlessly tradeable ${ }^{1}$ and they serve as numeraires. The industrial sector has imperfectly competitive firms producing differentiated goods under increasing returns to scale. The goods are traded with iceberg $\operatorname{cost}^{2}, \tau_{j, i}$. This implies that $\tau$ units have to be shipped from country $j$ so that one unit arrives in country $i$.

Following Dixit and Stiglitz (1977), production of a quantity $x_{i}(h)$ of any variety $h$ in any country $i$ requires the same fixed $(\alpha)$ and variable $\left(\beta x_{i}(h)\right)$ quantities of the production input. The cost function of a firm producing variety $h$ in country $i$ is $c_{i}(h)=w_{i}\left(\alpha+\beta x_{i}(h)\right)$, where $w_{i}$ is the wage rate of workers in the industrial sector in country $i$.

There are two factors of production in each country; peasants and workers. Following Krugman (1981), each factor is assumed to be specific to one sector.

\footnotetext{
${ }^{1}$ As Dixit and Stiglitz (1980) mentioned, this good can be thought of as the time at the disposal of the consumers. Researchers such as Fujita, Krugman, and Venables (1996), and Hadar (1996) took into account positive trade costs for the homogeneous goods as well as differentiated goods, and then they studied an incentive for workers' migration from the rest of the world that may keep regional agglomeration within a country. However, Davis (1998) argued that (1) when transportation costs are identical for both types of goods, the home market effect vanishes, and (2) unless the relative costs of trading differentiated goods are unusually high, every country will produce them in exact proportion to its size. But Davis' (1998) framework differs in that the migration is ruled out in his 'open' economies between two countries. In our paper, we do not rule out the possibility of migration between members and non-members of an RTA.

${ }^{2}$ Under the assumption of an iceberg transport cost, CES utility and monopolistic competition implies that spatial price discrimination is equivalent to mill pricing, which is only one of several alternatives, such as uniform delivered pricing. Such a consideration would be important when one is serious about a firm's various pricing policies in a region. See Ottaviano and Thisse (1998) for more details.
} 
Peasants produce commodities, and workers produce industrial goods. The peasant population is assumed to be completely immobile between countries with a given peasant supply $(1-\mu) / M$ in each country. Workers may move between countries. If $L_{i}$ is the worker supply in country $i$, the total number of workers is assumed to be $\Sigma_{i=1}^{M} L_{i}=\mu$. In Krugman and Venables (1995) and Puga and Venables (1997), workers are assumed to be mobile nationally but not internationally. In the latter paper, workers are not mobile even within a regionally integrated market.

The representative consumer in each country has Cobb-Douglas preferences over a commodity and a CES aggregate of the industrial goods; $U=C_{i}^{\mu} C^{1-\mu}$, where $C$ is consumption of the numeraires and $C_{I}$ is consumption of the aggregated industrial goods. The parameter, $\mu$, indicates a share of expenditure on industrial goods ${ }^{3}$. The $C_{I}$ is defined by

$$
C_{I}=\left[\sum_{j=1}^{M} \int_{h \in n_{j}} c_{j, i}(h)^{(\sigma-1) / \sigma} d h\right]^{\frac{\sigma}{\sigma-1}}
$$

where $n_{j}$ is the large number of potential products in a country $j$, and $\sigma$ is the elasticity of substitution between varieties $(\sigma>1)$, which is assumed to be the same in all countries. The higher the substitutability, the closer substitutes the varieties ${ }^{4}$.

\section{B. Equilibrium Conditions}

In this section, I derive (1) a demand within a country for varieties from all countries, (2) a profit maximizing condition, (3) a zero profit condition and (4) a factor market clearing condition, all of which are elements of equilibrium analysis.

First, let $c_{j, i}(h)$ be the consumption in country $i$ of a representative country $j$ product. The prices in country $i$ are $p_{j, i}(h) \tau_{j, i}$ if $j \neq i$ and $p_{j, i}(h)$ if $j=i$. Then the demand for a representative product is in general:

$$
x_{j, i}(h)=p_{j, i}(h)^{-\sigma}\left(\frac{\tau_{j, i}}{q_{i}}\right)^{1-\sigma}\left[\mu m_{i}\right]
$$

${ }^{3}$ In Krugman (1991), this is one of the key parameters that determine whether countries converge or diverge. However, I am going to fix this parameter in this paper to see the effect of trade costs on a firm's choice of location.

${ }^{4}$ In Krugman (1991), this is also one of the key parameters that determine whether countries converge or diverge. Although $\sigma$ is a parameter of tastes, it was used as an inverse index of economies of scale in equilibrium. However, I am going to fix this parameter in this paper to see the effect of trade costs on a firm's choice of location. 
where $m_{i}$ is the income of country $i$ equal to $(1-\mu) / M+w_{i} L_{i}$ and $q_{i}$ is the price index of the industrial aggregates. However, this price index is considered to be a constant value. Since the number of varieties produced is large as in a Chamberlinian model, the effect of the price of any one variety on the demand for any other will be negligible. So each firm can ignore the effect of its actions on other firm's behavior.

Second, when firms sell in each country, they perceive a constant own price demand elasticity of $\sigma$ in every market. All firms producing in any particular location have the same profit maximizing FOB price, which is a constant relative mark-up over the marginal cost:

$$
p_{i}=\frac{\sigma \beta}{\sigma-1} w_{i}
$$

This implies that $p_{i} / p_{j}=w_{i} / w_{j}$ for $i \neq j$.

Third, when firms enter and exit in response to $(+)$ and $(-)$ profits, an equilibrium in industrial sector profits will be exhausted in every country. That is,

$$
x=\frac{\alpha(s-1)}{\beta}
$$

Lastly, the following is the labor market clearing condition for a country $j \in M$ :

$$
L_{i}=\int_{h \in n_{i}} L_{i}(h) d h=n_{i} \alpha \sigma
$$

The number of manufactured goods produced in each country is proportional to the number of workers. This also implies that $n_{i} / n_{j}=L_{i} / L_{j}$ for $i \neq j$.

\section{Short Run Equilibrium and Long Run Equilibrium}

Short run equilibrium will be defined in a Marshallian way, as an equilibrium in which the allocation of workers between countries may be taken as given. However in the long run, workers start to recognize their real wage relative to the other countries. So workers may move towards the economy that offers them higher real wages, leading to either convergence between countries as they move toward equality of the worker/peasant ratio or divergence as the workers all congregate in one country.

In the short run, the total income of country $i$ workers is equal to the total 
spending on these products in all countries. Therefore,

$$
w_{i} L_{i}=\mu \sum_{j=1}^{M}\left\{\frac{n_{i} p_{i} x_{j, i}}{\sum_{i=1}^{M} n_{i} p_{i} x_{j, i}} \times m_{j}\right\} \text { and } m_{j}=\frac{1-\mu}{M}+w_{j} L_{j}
$$

This system of equations determines nominal wages, $w_{i}$ in the short run, in which the allocation of workers stays the same. Note that if $M=2$, then the model turns out to be Krugman's (1991) 2-region case. For the purpose of comparison, see the Appendix for these conditions when $M=3$. I will use these conditions in the next section to highlight the effect of the formation of an RTA on production patterns.

In the long run, however, workers may move based on the relative size of the real wage. To discover the real wage in each country, I need to figure out the price index for manufactured goods for consumers residing in that country. The following are the real wage and the price indices when $f_{i}=L_{i} / \mu$ is the share of the manufacturing labor force in country $i$.

$$
\omega_{i}=w_{i} q_{i}^{-\mu}
$$

where $q_{i}=\frac{\alpha \beta}{\sigma-1}\left(\frac{\mu}{\alpha \beta}\right)^{\frac{1}{1-\sigma}}\left[f_{i}\left(w_{i}\right)^{1-\sigma}+f_{j}\left(w_{j} \tau_{j, i}\right)^{1-\sigma}+f_{k}\left(w_{k} \tau_{k, i}\right)^{1-\sigma}\right]^{\frac{1}{1-\sigma}}$.

When $\omega_{i} / \omega_{j}>1(<1)$, the workers move to country $i$ (country $j$ ) in the long run. Such a relative size of real wage among countries allows us to see the pattern of economic geography when some of the parameters change, and I am particularly interested in the effect of the formation of regional trade agreements on economic geography.

\section{Regional Trade Agreement and the Location of Firms}

In this section, I wish to show that the equal distribution of manufacturing industries among three countries becomes unstable after two of the countries form a regional trade agreement by reducing their internal trade costs. When two countries form an RTA, the firms in the rest of the world have an incentive to move into the RTA because the workers will move into the larger market where they find 
a higher real wage in the long run, which will be a reason for a firm to find it profitable to enter an RTA. The increase in the real wage of the countries in the RTA is a result of the following forces.

The first force comes from an expenditure effect. The existing workers in the RTA can spend more due to the reduction of internal trade costs. As it becomes more profitable for the existing firm to produce more varieties, the firm requires additional workers. All other things being equal, this increased demand for labor will increase the nominal wage in the short run. In the long run, the higher the wages in the RTA, the lower the wages in the rest of the world, and the reduction of internal trade costs works to increase the relative real wage of the RTA compared to that of the rest of the world. Therefore, production will shift into the RTA area once it is formed.

As such a movement of production and workers continues, it is expected that labor competition within the RTA will increase. Since the RTA makes its market larger than the rest of the world, the workers of the RTA will face stiff competition, which induces a decrease in the nominal wage. The labor competition effect works to stop the production shifting-in effect eventually at some point in time.

The next two subsections will show how I achieved these results using numerical experiments with the equilibrium conditions (6) and (7) when $M=3$.

\section{A. Before the Formation of the RTA}

Let me assume that all countries are symmetric with $L_{1}=L_{2}=L_{3}$ and that before the formation of the RTA between country 1 and 2, internal trade costs $\left(\tau_{1,2}=\tau_{2,1} \equiv \tau\right)$ and external trade costs $\left(\tau_{1,3}=\tau_{3,1}=\tau_{2,3}=\tau_{3,2} \equiv \tau\right)$ are the same. Then from the short run equilibrium condition in (6), I can verify that nominal wages in all countries will be the same, $w_{1}=w_{2}=w_{3}$. Furthermore, it is not difficult to see from the long run real wage equations in (7) that the relative real wages are also all identical for all countries, $\omega_{1}=\omega_{2}=\omega_{3}$. As a result, the workers have no incentive to move from their countries to any other countries.

\section{B. After the Formation of the RTA}

Now, given this symmetric specification, what if countries 1 and 2 formed an RTA? Note that both $L_{1}=L_{2}=L_{3}$ and the formation of the RTA between countries 1 and 2, imply that $\left(L_{1}+L_{2}\right)>L_{3}$. To analyze the consequences for both the integrating countries and the rest of the world, let us remove only the internal trade cost, and keep the external trade cost unchanged, that is, $1=\tau^{R T A}<t$. 
Figure 3. (a) Before RTA, (b) After RTA

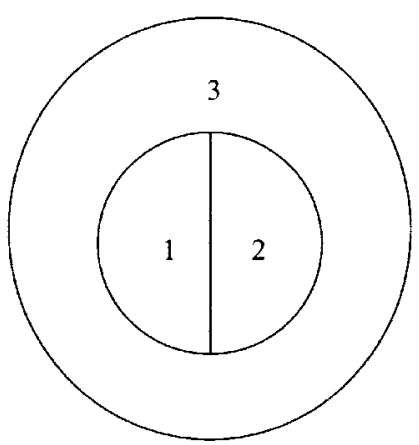

(a) Before RTA

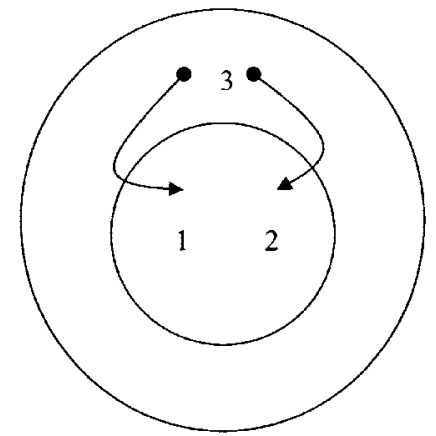

(b) After RTA

Since I start out with a symmetric world, the nominal wages within the RTA must be equalized even after the formation of the RTA, $w_{1}=w_{2}$. However, the formation of the RTA creates a nominal wage gap between the RTA members and non-RTA members for the following reasons.

First, since the internal trade costs are removed, the workers' expenditure will increase relatively, so that it is more profitable for firms to produce within the RTA. This, in turn, creates more demand for workers in RTA regions. This will increase nominal wages within the RTA countries above those in the rest of the world. In a symmetric world with parameter specifications such as $f_{1}=f_{2}=f_{3}=1 / 3$, $1=\tau^{R T A}<t, \alpha=3$ and $\alpha=1 / 3$, using the equation (6), one can readily calculate the nominal wage gaps between the RTA and non-RTA areas, $w_{1}=w_{2}>w_{3}$.

Second, however, in the long run, workers start to perceive the real wage differences between countries within an RTA and the rest of the world. A worker's real wage in equation (7) is affected by the nominal wages not only of his own country but also of other countries through the price index. When the internal trade costs drop within the RTA, the nominal wage of the members increases. This has a direct positive effect on the real wages of RTA members. Moreover, the price index is positively affected by a combination of the reduction of internal trade costs, of the higher wages in member countries, and of the lower wages in nonmembers. A simple calculation for (7) also shows that the real wage effect of an RTA member is positive, so the formation of the RTA would create an incentive for workers to move into the RTA from the rest of world.

Lastly, since the sum of workers in the RTA member countries becomes larger and larger as the process of movements of production and workers proceeds, there will be an increase in labor competition within the RTA. This plays a role in reducing the 
nominal wage in the short run, which will stop such movements at some point in time. See Figure 3(a) and (b), and proposition 1 summarizes this result.

Proposition 1 Suppose that there are three countries in the world and that the sizes of all countries are equal (for example, $f_{1}=f_{2}=f_{3}=1 / 3$ ). Furthermore, suppose that initially the trade costs are high before the formation of the RTA ( $\dot{t}=\dot{t}=6)$ and that other parameters are $\sigma=3$ and $\mu=1 / 3$.

(a) Before the formation of an RTA between countries 1 and 2, all workers and firms would not move from their countries (Evenly distributed long run equilibrium).

(b) After the formation of an RTA between countries 1 and 2, the production will shift into the RTA from the rest of the world (Divergence or Production shifting-in effect).

Proposition 1 for a symmetric case replicates the qualitatively same result as in Baldwin and Venables (1995) and Puga and Venables (1997). This result is robust in that, once countries form regional trade agreements, the production shifting-in effect is always expected. However, in the next section, I will show that the industrial structure resulting from the production shifting-in effect could be unstable in respect of a later increase in the level of external trade costs.

\section{A Firm's Incentive to Defect from Local Manufacturing Concentrations}

In this section I start out with the Puga and Venables (1997) situation in which all manufacturing firm's are concentrated in one member of the RTA. The purpose of this section is to discover the instability of industrial structure resulting from the production shifting-in effect to a later increase in external trade costs, by examining a firms incentive to move to the rest of the world when the external trade costs become higher.

Suppose that there are three countries, 1, 2 and 3 in the world and that trade costs are defined as $\tau_{1,2}=\tau_{2,1} \equiv \tau$ and $\tau_{3,1}=\tau_{2,3}=\tau_{2,3}=\tau_{3,2} \equiv t$.

Now consider a situation in which all workers and manufacturing firms are concentrated in country 1 . Country 1 , then, will be the largest market in the world. Since a share of total income, $\mu$, is spent on manufactures and all this income goes to country 1 , we find the following income ratio between countries.

$$
\frac{m_{2}}{m_{1}}=\frac{m_{3}}{m_{1}}=\frac{1-\mu}{1+2 \mu}
$$

Then each firm in country 1 will have a value of sales equal to the following expression: 


$$
V_{1}=\left(\frac{\mu}{n}\right)\left(m_{1}+m_{2}+m_{3}\right)
$$

where $n$ is the total number of manufacturing firms concentrated in country 1 .

Now let us think about an incentive for a firm to defect from this situation. A firm may defect to relocate in either country 2 or country 3 . If it does not defect, then concentration of production in country 1 is in equilibrium, and if it does defect, the concentration is not in equilibrium. In fact, the questions that I want to clarify here are under what condition the formation of the RTA makes this equilibrium unstable and how it makes the firm defect.

\section{A. An Incentive to Move from Country 1 to Country 2}

In order for a defecting firm to relocate production to country 2 , the firm must be able to attract workers. To do so, it must compensate them for the fact that all manufactures must be imported. So the relative nominal wages between 1 and 2 must be

$$
\frac{w_{2}}{w_{1}}=\tau^{\mu}
$$

Given this higher wage, the firm will charge a profit-maximizing price that is higher than that of other firms in the same proportion. Now I can derive the value of the firms sales using this fact.

In country 1 , the defecting firm's value of sales will be the value of sales of a representative firm times $\left(w_{2} \tau / w_{1}\right)^{1-s}$. In country 2 , its value of sales will be that of a representative firm times $w_{2} /\left(w_{1} \tau\right)^{1-s}$. So the total value of the defecting firms sales will be:

$$
V_{2}=\left(\frac{\mu}{n}\right)\left[\left(\frac{w_{2} \tau}{w_{1}}\right)^{1-\sigma} m_{2}+\left(\frac{w_{2}}{w_{1} \tau}\right)^{1-\sigma} m_{2}+m_{3}\right]
$$

Note that trade costs work to the defecting firm's disadvantage in its sales to consumers in country 1, but work to its advantage in sales to people in country 2 . Note also that when the cost is zero, the sales in country 1 and 2 are the same. As the cost increases, the sales of the defecting firm will change negatively due to the first term in (11) and positively due to the second term in (11).

From these equations in (9), (10) and (11), I can derive the ratio of the value of sales by this defecting firm to the sales of firms in country 1 : 
Figure 4. An Incentive for a Firm to Move to Country 2 or 3

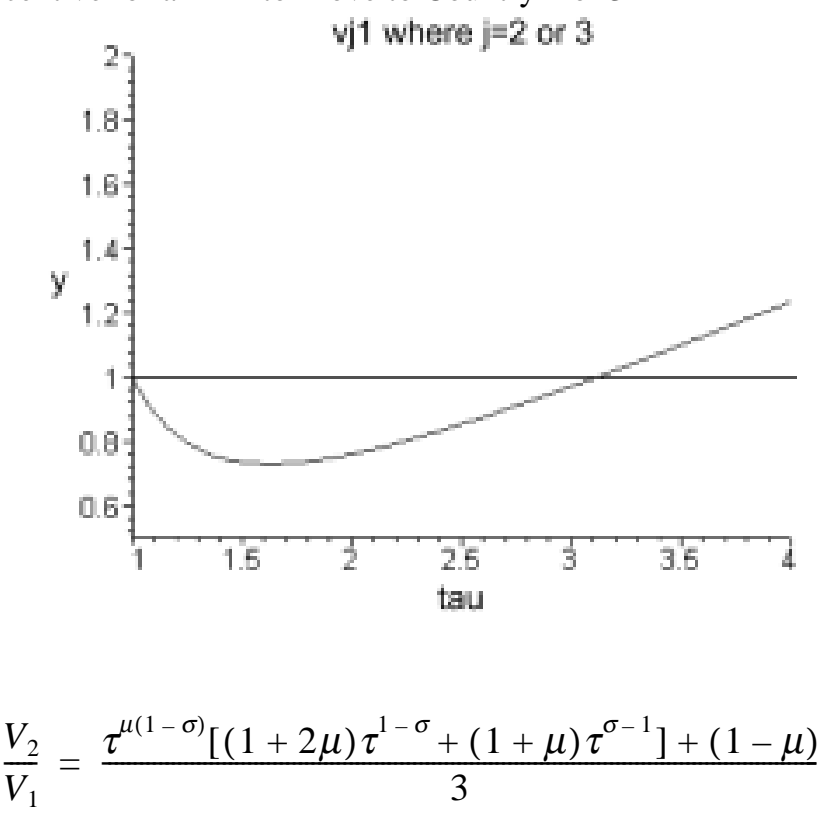

However, because fixed costs are higher in country 2 due to the higher wage rate, the defecting firm must have the ratio $V_{2} / V_{1}>w_{2} / w_{1}=\tau^{\mu}$. Now let me define a new variable $v_{2,1}=\left(V_{2}(\tau) / V_{1} \tau^{\mu}\right)$ as follows.

$$
v_{2,1}=\frac{\tau^{-\mu \sigma}\left[(1+2 \mu) \tau^{1-\sigma}+(1+\mu) \tau^{\sigma-1}\right]+\tau^{-\mu}(1-\mu)}{3}
$$

When $v_{2,1}>1$, the relative value of sales by the defecting firm compared to the value of sales in country 1 is greater than the fixed costs for the firm to attract workers from country 1 to country 2 , that is, $V_{2} / V_{1}>w_{2} / w_{1}$. Therefore, it is profitable for a firm to move and begin production in country 2 if all other manufacturing production is concentrated in country 1 ; when $v_{2,1}<1$, it is not profitable.

The Figure 4 is a graphic representation of the relations of the incentives for deviations $\left(v_{2,1}\right)$ and trade costs when $\sigma=3$ and $m=0.3$. This shows that when the trade costs between countries vary within a very small range, the $v_{2,1}$ will be less than or equal to 1 . As the costs increase beyond some critical level, the firms relative value of sales will be higher than 1 when it defects to country 2 .

\section{B. Incentive to Move from Country 1 to Country 3}

In the same way, if the defecting country decides to produce in country 
$3, v_{3,1}=\left(V_{3}(t) / V_{1} t^{\mu}\right)$ will be a function of external trade cost $t$, instead of $\tau$. We simply replace $\tau$ with $t$ !

$$
v_{3,1}=\frac{t^{-\mu \sigma}\left[(1+2 \mu) t^{1-\sigma}+(1+\mu) t^{\sigma-1}\right]+t^{-\mu}(1-\mu)}{3}
$$

Again, for the same reason, when $v_{3,1}>1$, it is profitable for a firm to move and begin production in country 3 if all other manufacturing production is concentrated in country 1 ; when $v_{3,1}<1$, it is not profitable. The same Figure 4 will be used for the analysis.

Next, I am going to consider a stable asymmetric equilibrium where all manufacturing firms are concentrated in country 1 with a zero internal trade barrier and a positive external trade barrier. Then I will show that when the external trade costs are too high, the firm will defect and move to country 3 .

\section{Instability of the Industrial Structure Resulting from the Production Shifting-In Effect to a Later Increase in the External Trade Costs}

Now suppose that country 1 and country 2 form an RTA and accordingly remove their internal trade costs, $\tau=1$. Given the regional free trade agreement, the local manufacturing concentration in country 1 can be a stable asymmetric equilibrium when the external trade cost is positive. To see this situation, in Figure 4, find the crossing point between the line of $v_{3,1}$ with $t>1$ and the horizontal line at 1 . Let us call the related external trade cost $t^{*}$. When $\tau=1$ and $t=t^{*}, v_{2,1}=1=v_{3,1}$. Therefore there is no incentive for a firm in country 1 to defect from this equilibrium. In fact, this case is similar to what Puga and Venables (1997) showed in their model.

Now I claim that this asymmetric equilibrium will become unstable when the external trade costs are high enough. I will increase the common external trade cost to $t$ from $t^{*}$, and consider the effect on $v_{3,1}$. Refer to Figure 4 again and consider $v_{2,1}$ and $v_{3,1}$ as a function of trade costs $\tau$ and $t$, respectively.

First, since $t=1$ between countries 1 and $2, v_{2,1}=1$ in (13). This means that there is no incentive for a firm in country 1 to move to country 2 . This is point 1 on the vertical axis in Figure 4. Second, consider $v_{2,1}$, the incentive for a firm in country 1 to move to country 3 . When $t$ is $t^{*}$, Figure 4 shows that $v_{3,1}=1$ also. However, if $t$ increases above $t^{*}, v_{3,1}$ will be greater than 1. This implies that a firm facing a higher trade cost between an RTA and non-RTA country will have an incentive to move to the non-RTA area. Proposition 2 summarizes these results. 
Proposition 2. Suppose that there are three countries (1,2 and 3) in the world and all workers and manufacturing firms are concentrated in country 1.

(a) This can be a stable asymmetric equilibrium where the internal trade costs between countries 1 and 2 are removed and the external trade costs are still positive. That is, when $\tau=1$ and $t=t^{*}>1$, then $=1=$ in Figure 4

(b) This can be unstable when the external trade costs are higher than $t^{*}$, and as a result the firms begin to move to the non-RTA country. That is, when $\tau=1$ and $t>t^{*}>1$, then $v_{2,1}=1<v_{3,1}$ in Figure 4 .

The intuition for this result is as follows. Due to the manufacturing concentration in country 1 , all workers reside in country 1 . When a firm tries to move to country 3 , it has to attract a worker to move to country 3 as well. To do so, it has to compensate for the high fixed costs due to the high trade costs. With a higher wage in country 3 , the worker will spend more money in country 3 . Moreover, given the higher wage, the defecting firm will set a higher profit-maximizing price in country 3 . Since the peasant in country 3 also has to pay the higher price to buy the variety produced by the defecting firm, the defecting firms revenue will be higher in country 3 than in country 1 . As a result, it would be more profitable for the firm to move to the rest of the world.

\section{Concluding Remark}

The production shifting-in effect of an RTA has been argued for by several economic geography theorists such as Baldwin and Venables (1995) and Puga and Venables (1997). However the empirical evidence has seemed ambiguous.

In this paper, I re-examined an industrial structure resulting from the production shifting-in effect of an RTA. In particular I focused on a later increase in the external trade costs. To examine this issue, I extended Krugmanl's (1991) economic geography model such that workers are hired by manufacturing firms across multiple nations.

First, I replicated the production shifting-in effect of an RTA in this extension of Krugmans model. That is, I showed that a regional integration which drops its internal trade costs below given external trade costs always pulls industry to its region and benefits the members. The outside manufacturing firms find it profitable to move in and serve the inside market of the regional integration since it gives the inside market cost advantages.

Next, to check the sensitivity of the industrial outcome resulting from the production shifting-in effect, I considered a stable asymmetric equilibrium where workers and manufacturing firms are concentrated in one member country of the 
RTA with zero internal trade costs and positive external trade costs, and demonstrated what would happen if the external trade costs become higher. I showed that when the exogenous external trade costs become higher, the inside manufacturing firms of the integrated region begin finding it profitable to move out and serve the outside market. This is because the costs of attracting manufacturing workers are less than the revenues from both workers and peasants due to the higher profitmaximizing price.

This result shows that the industrial structure resulting from the production shifting-in effect of an RTA, to be stable, may need non-higher external trade costs in an economic geography model with mobility of workers, which could not be shown in the previous economic geography literature due to the assumption of the immobility of workers.

\section{Acknowledgements}

I would like to thank Professor Robert E. Baldwin, Professor Robert W. Staiger, Professor M. Scott Taylor and Professor Yeon-Koo Choi of the University of Wisconsin-Madison for their helpful comments in seminars.

Received 8 August 2002, Accepted 9 March 2002

\section{References}

Bagwell, Kyle, and Robert W. Staiger (1997), "Regionalism and Multilateral Tariff Cooperation," National Bureau of Economic Research, Working Paper \#5921.

Bagwell, Kyle, and Robert W. Staiger (1999), "Regionalism and Multilateral Tariff Cooperation," in J. Piggott and A. Woodland (eds.), International Trade Policy and the Pacific Rim, London: Macmillan.

Baldwin, Richard and A.J. Venables (1995), "Regional Economic Integration," in G.M. Grossman and K.Rogoff, eds., Handbook of International Economics 3, Elsevier, Amsterdam, 1597-1644.

Davis, Donald R. (1998), "The Home Market, Trade and Industrial Structure," American Economic Review, 88(5), 1264-1276.

Dixit, Avinash K. and J.E. Stiglitz (1997), "Monopolistic Competition and Optimum Product Diversity," American Economic Review, 67, 297-308.

Fujita, Masahisa, P. Krugman, A.J. Venables (1996), "Agricultural Transport Costs," mimeo.

Hadar, Yossi (1996), "Homegeneous Products Transportation Costs and Their Effects," 
mimeo, London School of Economics.

Krugman, Paul (1981), "Scale Economies, Product Differentiation and the Pattern of Trade," American Economic Review, 70, 950-959.

Krugman, Paul (1991), "Increasing Returns and Economic Geography," Journal of Political Economy, 99, 483-499.

Krugman, Paul and A.J. Venables (1995), "Globalization and the Inequality of Nations," Quarterly Journal of Economics, 110, 857-880.

Ottaviano, Gianmarco and Jacques-Francois Thisse (1998), "Agglomeration and Trade

Revisited," Centre for Economic Policy Research, Discussion Paper \#1903.

Puga, Diego and A.J. Venables (1997), "Preferential Trading Arrangements and Industrial Locaion," Journal of International Economics, 43, 347-368.

Richardson, Martin (1993), "Endogenous Protection and Trade Diversion," Journal of International Economics, 34(3-4), 309-324.

\section{Appendix: Short Run Equilibrium Equations $(M=3)$}

$$
w_{1} L_{1}=\mu\left\{\begin{array}{l}
\frac{1}{1+\left(\frac{L_{2}}{L_{1}}\right)\left(\frac{w_{2}}{w_{1}} \tau_{1,2}\right)^{1-\sigma}+\left(\frac{L_{3}}{L_{1}}\right)\left(\frac{w_{3}}{w_{1}} \tau_{1,3}\right)^{1-\sigma} \times m_{1}} \\
+\frac{1}{\left(\frac{L_{1}}{L_{2}}\right)\left(\frac{w_{1}}{w_{2}} \tau_{2,1}\right)^{1-\sigma}+1+\left(\frac{L_{3}}{L_{2}}\right)\left(\frac{w_{3}}{w_{2}} \tau_{2,3}\right)^{1-\sigma} \times m_{2}} \\
+\frac{\left(\frac{L_{1}}{L_{3}}\right)\left(\frac{w_{1}}{w_{3}} \tau_{3,1}\right)^{1-\sigma}}{\left(\frac{L_{1}}{L_{3}}\right)\left(\frac{w_{1}}{w_{3}} \tau_{3,1}\right)^{1-\sigma}+\left(\frac{L_{2}}{L_{3}}\right)\left(\frac{w_{2}}{w_{3}} \tau_{3,2}\right)^{1-\sigma}+1} \times m_{3} \\
+\frac{\left(\frac{L_{2}}{L_{1}}\right)\left(\frac{w_{2}}{w_{3}} \tau_{1,2}\right)^{1-\sigma}}{\left(\frac{L_{1}}{L_{3}}\right)\left(\frac{w_{1}}{w_{3}} \tau_{3,1}\right)^{1-\sigma}+\left(\frac{L_{2}}{L_{3}}\right)\left(\frac{w_{2}}{w_{3}} \tau_{3,2}\right)^{1-\sigma}+1}
\end{array}\right\}, m_{1}=\frac{1-\mu}{3}+w_{1} L_{1}
$$


The Effects of Regional Free Trade Agreements on Industrial Structure: An Extension of $\cdots . . . .59$

$$
w_{3} L_{3}=\mu\left\{\begin{array}{l}
\frac{\left(\frac{L_{3}}{L_{2}}\right)\left(\frac{w_{3}}{w_{2}} \tau_{2,3}\right)^{1-\sigma}}{\left(\frac{L_{1}}{L_{2}}\right)\left(\frac{w_{2}}{w_{1}} \tau_{2,1}\right)^{1-\sigma}+1+\left(\frac{L_{3}}{L_{1}}\right)\left(\frac{w_{3}}{w_{2}} \tau_{1,3}\right)^{1-\sigma}} \times m_{1} \\
\frac{\left(\frac{L_{3}}{L_{2}}\right)\left(\frac{w_{3}}{w_{2}} \tau_{2,3}\right)^{1-\sigma}}{\left(\frac{L_{1}}{L_{2}}\right)\left(\frac{w_{1}}{w_{2}} \tau_{2,1}\right)^{1-\sigma}+1+\left(\frac{L_{3}}{L_{2}}\right)\left(\frac{w_{3}}{w_{2}} \tau_{2,3}\right)^{1-\sigma}} \times m_{2} \\
+\frac{1}{\left(\frac{L_{1}}{L_{3}}\right)\left(\frac{w_{1}}{w_{3}} \tau_{3,1}\right)^{1-\sigma}+\left(\frac{L_{2}}{L_{3}}\right)\left(\frac{w_{2}}{w_{3}} \tau_{3,2}\right)^{1-\sigma}+1} \times m_{3}
\end{array}\right\}, m_{3}=\frac{1-\mu}{3}+w_{3} L_{3}
$$

